\title{
Bilateral Cervical Fistulas from Heterotopic Salivary Gland Tissues
}

\author{
Kei Ogawa Kenji Kondoh Kaori Kanaya Atsushi Ochi \\ Takashi Sakamoto Tatsuya Yamasoba \\ Department of Otorhinolaryngology - Head and Neck Surgery, Graduate School of Medical \\ Sciences, University of Tokyo, Tokyo, Japan
}

\section{Key Words}

Heterotopic salivary gland · Ectopic salivary gland · Salivary gland heterotopia - Salivary gland choristoma $\cdot$ Branchial cleft anomalies

\begin{abstract}
A 24-year-old male was referred to our department with intermittent clear drainage in both sides of the middle neck that did not increase while eating. On physical examination, there were fistulas in both sides of the neck, anterior to the sternocleidomastoid muscles. Fistulography revealed a 9-mm-long sinus from the left fistula, extending in the medial-caudal direction. On the right side, cannulation was not possible. Surgical excision of the lesion was performed on both sides, and the pathological examination revealed heterotopic salivary gland tissue (HSGT). From a literature review of reports of bilateral neck HSGT, we found that it is often associated with a family history of HSGT and other congenital anomalies. However, our case was different from the previously reported cases in that, although it was a bilateral case, it lacked any family history of HSGT or other congenital anomalies. Clinicians should include HSGT in the differential diagnosis of neck sinuses.

(C) 2015 S. Karger AG, Basel
\end{abstract}

\section{Introduction}

Heterotopic salivary gland tissue (HSGT) is a rare clinical entity. HSGT has been observed in various locations throughout the body, but mainly in the head and neck region. HSGTs sometimes involve neoplastic lesions, including malignant lesions, so we should consider HSGT in the differential diagnosis of neck sinus. Many of the previously reported HSGTs are unilateral. Bilateral neck HSGTs are extremely rare. The present report describes a case of bilateral neck HSGT. 
Ogawa et al.: Bilateral Cervical Fistulas from Heterotopic Salivary Gland Tissues

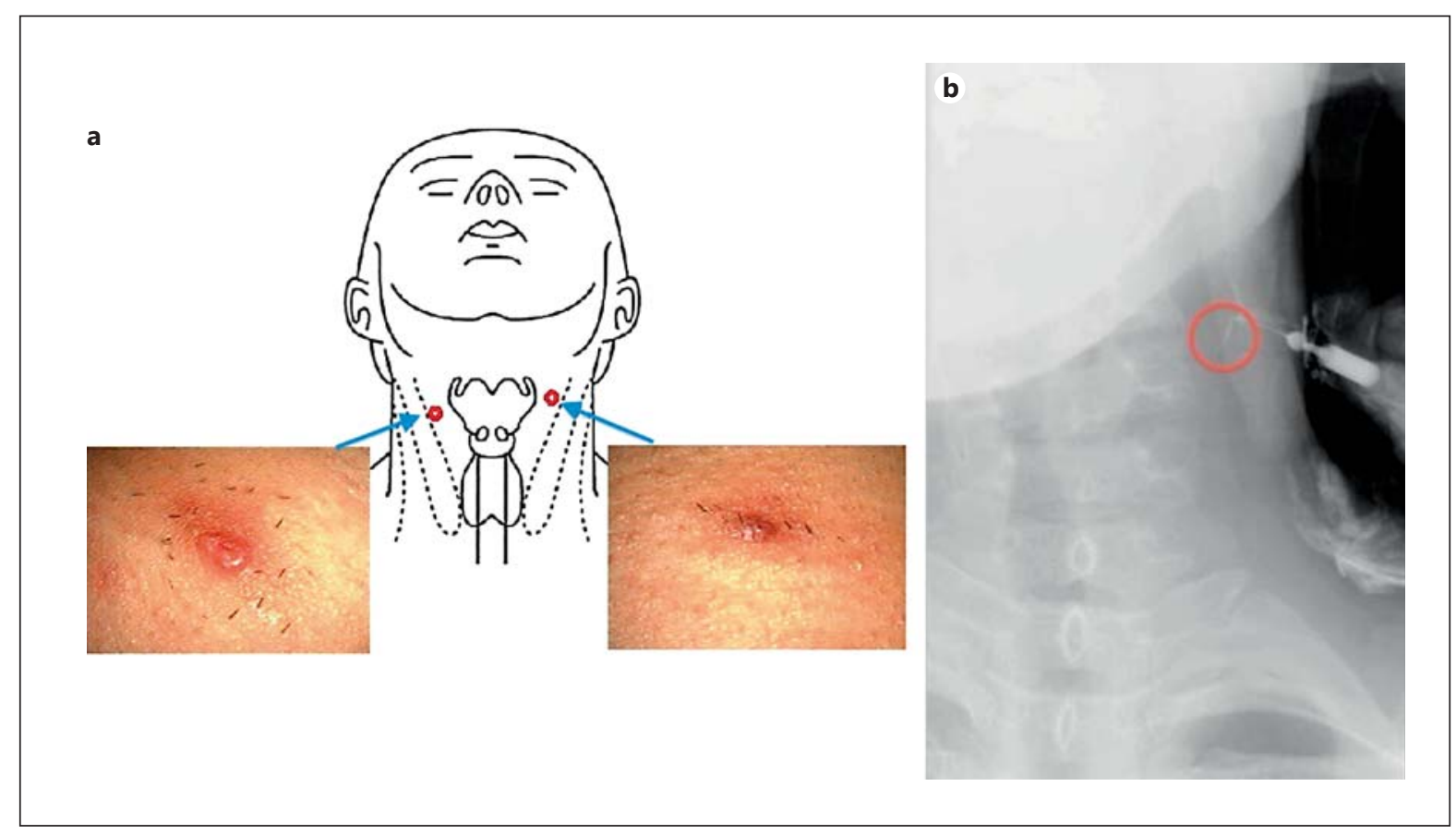

Fig. 1. a A schematic drawing and photographs showing the locations and appearance of the skin lesions. b An anterior-posterior view of the fistulography of the left sinus. The sinus extends about $9 \mathrm{~mm}$ in the medial-caudal direction (circle). There is no cystic lesion at the end of the sinus.

\section{Case Report}

An otherwise healthy 24-year-old male was referred to our department with intermittent clear drainage in both sides of the middle neck. He reported that the drainage had been present since childhood and that the amount of drainage was not affected by eating. There were no signs to suggest acute infection in the neck. He had no family history of congenital anomalies.

On physical examination, there were fistulas on both sides of the neck, anterior to the sternocleidomastoid muscles. The right fistula was located at the median level of the thyroid cartilage, and the left fistula was located about $5 \mathrm{~mm}$ more rostral than the right fistula. The fistulas were slightly wet and reddish but did not hurt, and no mass was palpable beneath the lesion (fig. 1a).

Further examinations, including endoscopic inspection of the head and neck region, ultrasonography of the neck and neck magnetic resonance imaging, were performed to rule out a subclinical lesion of the head and neck. None of the studies showed any abnormality. Ultrasonography of the kidneys and pure-tone audiometry were also performed, and there were no findings to suggest branchio-otorenal syndrome.

Fistulography demonstrated that there was a 9-mm-long sinus from the left fistula extending in the medial-caudal direction (fig. 1b). There was no cystic lesion at the end of the sinus. On the right side, cannulation was not possible. Preoperative differential diagnosis included second branchial cleft anomalies and sinuses associated with HSGT, but we suspected that the former was unlikely, since it usually has a long extension towards the tonsillar fossa.

Total surgical excision of the lesion was performed under general anesthesia using surgical microscopy. First, the left sinus was probed with a lacrimal probe, which could be inserted for approximately $9 \mathrm{~mm}$, as expected based on the results of the fistulography. Next, an elliptical incision was made on a skin crease around the fistula, and dissection was carried out along the extent of the probed tract. During the dissection, we noticed white glossy tissue at the end of the tract that extended into the platysma, and we excised it along with the sinus (fig. 2a). On the right side, probing was not possible. Dissection was similarly carried out using microscopy, and there was also white glossy tissue beneath the fistula that extended into the subcutaneous 
Fig. 2. The surgical specimen from the left (a) and right side (b). The circle indicates white glossy tissue at the end of the dissected tract, which extends into the platysma.
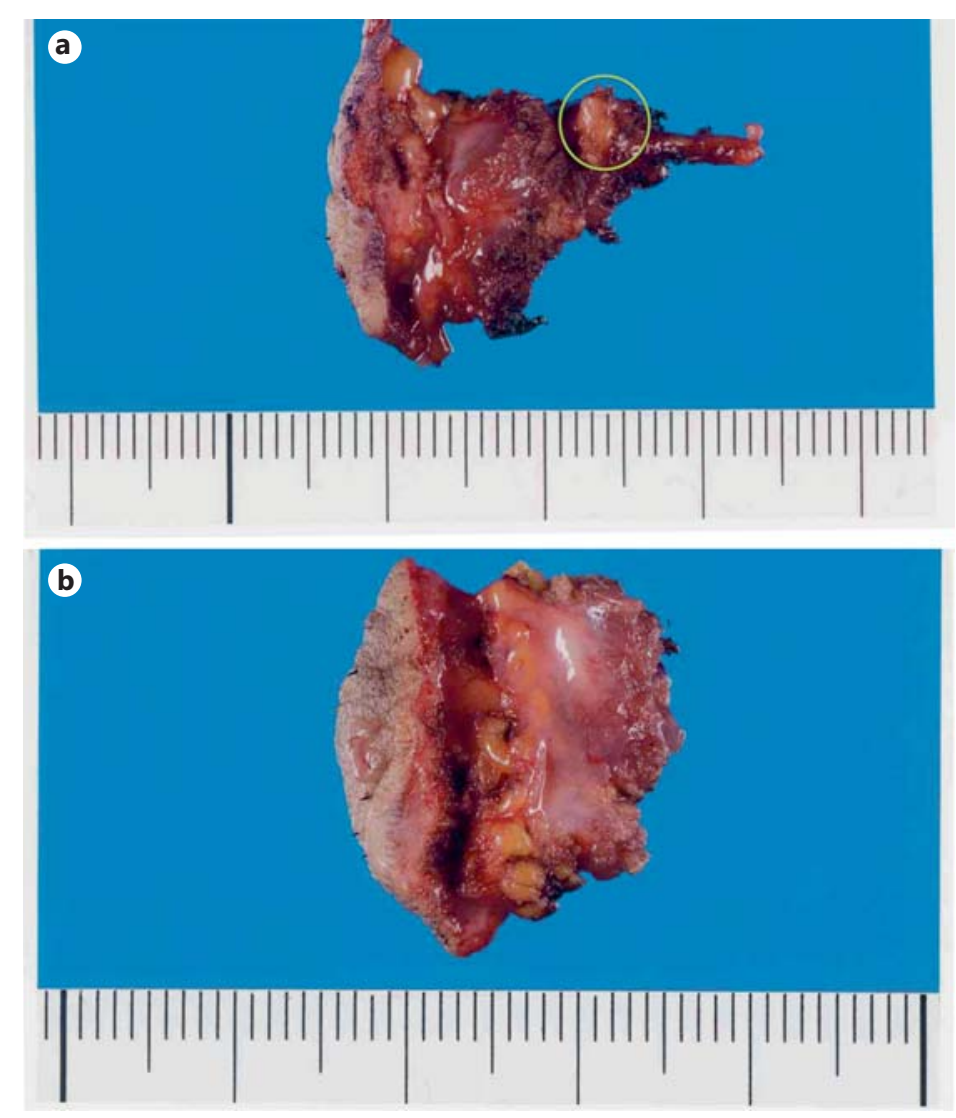

tissue (fig. 2b). After excision, the wound was irrigated with saline and sutured. The patient had an unremarkable postoperative course with no complications. The drainage completely stopped after the operation.

Pathological examination of the specimens revealed mucus-type salivary gland tissues with a glandular duct leading toward the skin surface (fig. 3). No neoplastic lesion was found in the specimen.

\section{Discussion}

Klimko and Horanyi [1] first described a case of histologically diagnosed HSGT in 1958. Since then, HSGT has been reported in various body regions, including the pituitary, middle and external ear, mandible, gingiva, frontal skin, tongue, tonsils, maxilla, oral palate, colon, vagina, prostate, breast, parathyroid gland, and cervical lymph nodes [2].

In previous reports, HSGT in the neck was mainly located at the anterior end of the sternocleidomastoid muscle [2], at the most $2-3 \mathrm{~cm}$ above the manubrium sterni [3]. This finding suggests a possible association between HSGT and branchial cleft sinus. In fact, Takimoto and Kato [4] described branchial cleft fistula including salivary gland tissue, and Goodman et al. [5] reported a case with the combination of left-sided branchial cleft sinus and right-sided HSGT. However, the sinus from HSGT usually has a shorter length and therefore requires less extensive surgery for removal [6]. Therefore, several authors emphasize that it is important to make a distinction between branchial cleft anomalies and HSGT preoperatively [6], and physicians should be aware of the clinical significance of HSGT in order to make an accurate diagnosis of draining sinus in the neck, although it is very rare [7]. 
Fig. 3. Microscopic photographs of the specimens from the left (a) and right side (b). Both show mucus-type salivary gland tissue $(\times 400)$.
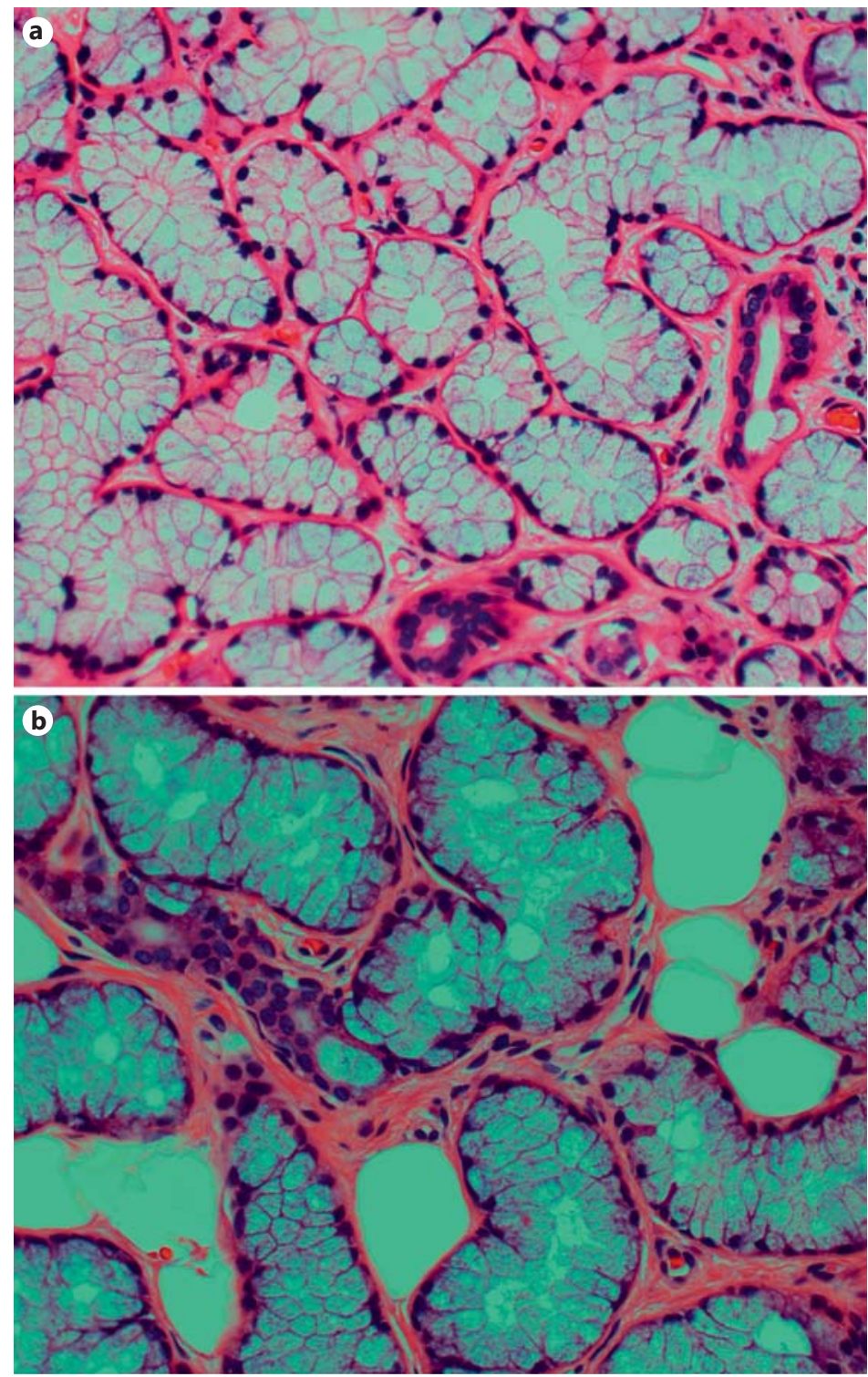

Previous reports also suggest that attention should be paid to concomitant neoplastic lesions, including malignant lesions, in patients with HSGT [6, 8]. Chang et al. [9] noted that HSGT was likely to be underdiagnosed before it underwent any neoplastic change. They also noted that when the lesion was suspected clinically, it should be totally excised to prevent further neoplastic changes, and all the sections should be cautiously checked.

We reviewed the clinical features of 48 cases of cervical HSGT without neoplastic transformation available on the PubMed database. There were 9 bilateral cases $[6,10-16]$. A summary of these bilateral cases is presented in table 1 . We found two characteristics common to bilateral cases. The first is family history: 4 patients had a family history of some cervical anomalies [10,12]. Hsu et al. [10] reported familial occurrence of HSGT, representing an autosomal dominant inheritance pattern. The second characteristic is the presence of other congenital anomalies: 3 patients had other congenital anomalies [11,13]. Of those, 2 patients had abnormal auricles, preauricular pits, and middle or inner ear anomaly [11], while the other patient had craniofacial anomalies and many other anom- 
Ogawa et al.: Bilateral Cervical Fistulas from Heterotopic Salivary Gland Tissues

Table 1. Summary of the clinical features of previously reported cases of bilateral HSGT of the neck

\begin{tabular}{|c|c|c|c|c|}
\hline First author, year & $\begin{array}{l}\text { Age at } \\
\text { operation, years }\end{array}$ & Gender & $\begin{array}{l}\text { Other congenital } \\
\text { anomalies }\end{array}$ & $\begin{array}{l}\text { Family history of } \\
\text { HSGT }\end{array}$ \\
\hline Hsu, 2006 [10] & 5 & female & none & $\begin{array}{l}\text { cousin, aunt, mother, } \\
\text { grandmother, etc. }\end{array}$ \\
\hline Joseph, 1986 [11] & not stated & female & preauricular pits & mother \\
\hline Joseph, 1986 [11] & 5 & female & preauricular pits & daughter \\
\hline Shvero, 1986 [12] & 2 & male & bilateral preauricular pits & sister, father \\
\hline Jensen, 2009 [13] & 10 & female & $\begin{array}{l}\text { multiple anomalies caused } \\
\text { by } 19 \mathrm{p} 13,12 \text { deletion }\end{array}$ & none \\
\hline Mair, 1977 [14] & 4 & female & none & none \\
\hline Nash, 1988 [15] & 6 & male & none & none \\
\hline $\begin{array}{l}\text { Sevila, } 1997 \text { [16] } \\
\text { Lassaletta-Atienza, }\end{array}$ & 11 & female & none & none \\
\hline $1998[6]$ & 3 & male & none & none \\
\hline
\end{tabular}

alies throughout her body [12]. In reviewing reports of 39 unilateral cases, a family history of HSGT or congenital anomaly was present in only 1 case (auricular pits and a family history of HSGT) [11]. Our case is different from the previously reported cases in that, although it was a bilateral case, it lacks either a family history of HSGT or congenital anomalies.

\section{Conclusion}

This report described a case of a patient with bilateral cervical fistulas from HSGT. HSGTs sometimes involve neoplastic lesions, including malignant ones. The sinus from HSGT usually has a shorter length and therefore requires less extensive surgery than branchial cleft sinus. Otolaryngologists should consider HSGT in the differential diagnosis of neck sinus.

\section{Acknowledgements}

This study was approved by the Institutional Review Board (protocol No. 2487) of the University of Tokyo Graduate School of Medicine. The authors declare that prior consent was obtained from the patient referred to in this report regarding the publication of all included information.

\section{Disclosure Statement}

The authors have no conflicts of interest to declare regarding the publication of this article.

\section{References}

1 Klimko D, Horanyi J: Congenital salivary fistulas of the neck (in French). J Chir (Paris) 1958;76:407-410.

2 Batsakis JG: Heterotopic and accessory salivary tissues. Ann Otol Rhinol Laryngol 1986;95:434-435.

-3 Soucy P: Congenital cervical salivary fistula. Can J Surg 1985;28:130-131.

4 Takimoto T, Kato H: Branchial cleft fistula with heterotopic salivary gland tissue in the lower neck. ORL J Otorhinolaryngol Relat Spec 1990;52:265-268. 
Ogawa et al.: Bilateral Cervical Fistulas from Heterotopic Salivary Gland Tissues

5 Goodman RS, Daly JF, Valensi Q: Heterotopic salivary tissue and branchial cleft sinus. Laryngoscope 1981;91: $260-264$.

-6 Lassaletta-Atienza L, Lopez-Rios F, Martin G, Benito A, Bronchalo F, Martínez-Tello FJ, Alvarez-Vicent JJ: Salivary gland heterotopia in the lower neck: a report of five cases. Int J Pediatr Otorhinolaryngol 1998;43: 153-161.

7 Hwang SM, Ahn SK, Lee SH, Lee WS: Heterotopic salivary glands simulating bronchial cleft fistular in the lower neck. J Dermatol 1996;23:287-289.

-8 Ferlito A, Bertino G, Rinaldo A, Mannarà GM, Devaney KO: A review of heterotopia and associated salivary gland neoplasms of the head and neck. J Laryngol Otol 1999;113:299-303.

-9 Chang WY, Lee KW, Tsai KB, Chen GS: Heterotopic salivary gland tissue: a case report demonstrating evolution and association with the branchial apparatus. J Dermatol 2005;32:731-736.

$\rightarrow 10$ Hsu RF, Hsu YC, Huang SC: Hereditary ectopic salivary gland: survey of three generations. Acta Otolaryngol 2006;126:330-333.

11 Joseph MP, Goodman ML, Pilch BZ, Bieber FR, Holmes LB, Reardon E: Heterotopic cervical salivary gland tissue in a family with probable branchio-otorenal syndrome. Head Neck Surg 1986;8:456-462.

12 Shvero J, Hadar T, Avidor I, Abraham A, Sidi J: Heterotopic salivary tissue and branchial sinuses. J Laryngol Otol 1986;100:243-246.

13 Jensen DR, Martin DM, Gebarski S, Sahoo T, Brundage EK, Chinault AC, Otto EA, Chaki M, Hildebrandt F, Cheung SW, Lesperance MM: A novel chromosome 19p13.12 deletion in a child with multiple congenital anomalies. Am J Med Genet A 2009;149A:396-402.

14 Mair IW, Bjorang G, Kearney MS: Heterotopic cervical salivary glands. J Laryngol Otol 1977;91:35-40.

15 Nash M, Cho H, Cohen J: Salivary choristomas in the neck. Otolaryngol Head Neck Surg 1988;99:590-593.

16 Sevila A, Morell A, Navas J, Alfonso R, Silvestre JF, Ramón R: Orifices at the lower neck: heterotopic salivary glands. Dermatology 1997;194:360-361. 